\title{
Using Administrative Data to Explore Potentially Aberrant Provision of Virtual Care During COVID-19: Retrospective Cohort Study of Ontario Provincial Data
}

Vess Stamenova ${ }^{1}, \mathrm{PhD}$; Cherry $\mathrm{Chu}^{1}, \mathrm{MSc}$; Andrea Pang ${ }^{2}$, MPH; Mina Tadrous ${ }^{1,2,3}, \mathrm{MSc}, \mathrm{PhD}$, PharmD; R Sacha Bhatia $^{1,2,4}$, MD, MBA; Peter Cram ${ }^{2,5}$, MD, MBA

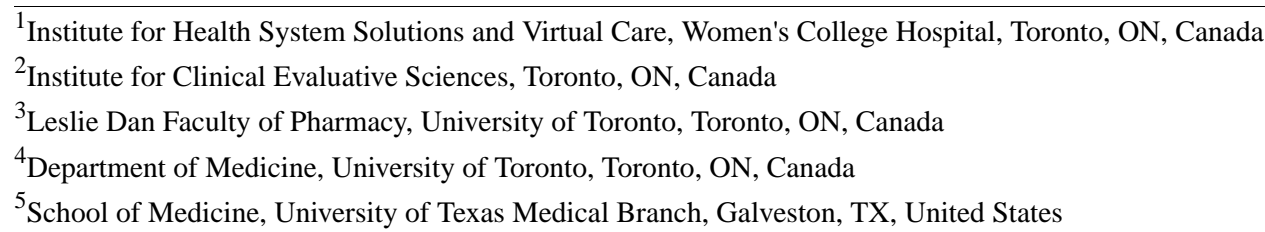

Corresponding Author:

Vess Stamenova, PhD

Institute for Health System Solutions and Virtual Care

Women's College Hospital

76 Grenville St

Toronto, ON, M5S 1B2

Canada

Phone: 14162680985

Email: vess.stamenova@wchospital.ca

\section{Abstract}

Background: The COVID-19 pandemic has led to a rapid increase in virtual care use across the globe. Many health care systems have responded by creating virtual care billing codes that allow physicians to see their patients over telephone or video. This rapid liberalization of billing requirements, both in Canada and other countries, has led to concerns about potential abuse, but empirical data are limited.

Objective: The objectives of this study were to examine whether there were substantial changes in physicians' ambulatory visit volumes coinciding with the liberalization of virtual care billing rules and to describe the characteristics of physicians who significantly increased their ambulatory visit volumes during this period. We also sought to describe the relationship between visit volume changes in 2020 and the volumes of virtual care use among individual physicians and across specialties.

Methods: We conducted a population-based, retrospective cohort study using health administrative data from the Ontario Health Insurance Plan, which was linked to the ICES Physician Database. We identified a unique cohort of providers based on physicians' billings and calculated the ratio of total in-person and virtual ambulatory visits over the period from January to June 2020 (virtual predominating) relative to that over the period from January to June 2019 (in-person predominating) for each physician. Based on these ratios, we then stratified physicians into four groups: low-, same-, high-, and very high-use physicians. We then calculated various demographic and practice characteristics of physicians in each group.

Results: Among 28,383 eligible physicians in 2020, the mean ratio of ambulatory visits in January to June 2020:2019 was 0.99 (SD 2.53; median 0.81, IQR 0.59-1.0). Out of 28,383 physicians, only 2672 (9.4\%) fell into the high-use group and only 291 $(1.0 \%)$ fell into the very high-use group. High-use physicians were younger, more recent graduates, more likely female, and less likely to be international graduates. They also had, on average, lower-volume practices. There was a significant positive correlation between percent virtual care and the 2020:2019 ratio only in the group of physicians who maintained their practice $(R=0.35$, $P<.001)$. There was also a significant positive correlation between the 2020:2019 ratio and the percent virtual care per specialty $(R=0.59, P<.01)$.

Conclusions: During the early stages of the pandemic, the introduction of virtual care did not lead to significant increases in visit volume. Our results provide reassuring evidence that relaxation of billing requirements early in the COVID-19 pandemic in Ontario were not associated with widespread and aberrant billing behaviors. Furthermore, the strong relationship between the 
ability to maintain practice volumes and the use of virtual care suggests that the introduction of virtual care allowed for continued access to care for patients.

(J Med Internet Res 2021;23(9):e29396) doi: 10.2196/29396

\section{KEYWORDS}

telemedicine; virtual care; COVID-19; pandemic; virtual health; telehealth; ambulatory visits; physicians; patients; digital health

\section{Introduction}

The COVID-19 pandemic has led to a rapid increase in virtual care use across the globe [1-5]. In Ontario, Canada's largest province, virtual care increased from $1.6 \%$ of all ambulatory visits pre-COVID-19 to $71 \%$ during the first wave of the COVID-19 pandemic [3], a much higher rate compared to those reported in other countries such as the United States (30\%) and Australia (42\%) [4,6,7].

While Ontario had pre-existing virtual care billing codes before the onset of the pandemic, these codes were allowable for a single government-run online platform and only available to specialists and primary care physicians in rostered patient practices or specialized practices. Primary care physicians outside of rostered practices were not included in this model, in order to support continuity of care [8] and respond to growing concerns about fragmentation and poor quality of care received in virtual walk-in clinics as well as funding disruptions in Canada [9] and abroad [10].

In Ontario, the pandemic led to the introduction of temporary billing codes in mid-March 2020 that reimbursed any physician with identical amounts for in-person, video, or telephone visits and eliminated prior restrictions on practice type or allowable technology platforms. This rapid liberalization of billing requirements, both in Canada and other countries [4], has led to concerns about potential abuse, but empirical data are limited [11].

The objectives of this study were to examine whether there were substantial changes in physicians' ambulatory visit volumes coinciding with the liberalization of virtual care billing rules and to describe the characteristics of physicians who significantly increased their ambulatory visit volumes during this period. We also sought to describe the relationship between visit volume changes in 2020 and the volumes of virtual care use in individual physicians and across specialties.

\section{Methods}

We conducted a population-based, retrospective cohort study using health administrative data from the Ontario Health Insurance Plan, which was linked to the ICES Physician Database. Data sets were linked using unique encoded identifiers and analyzed at ICES, an independent, nonprofit research institute. Use of these databases for the purposes of this study was authorized under $\$ 45$ of Ontario's Personal Health Information Protection Act, which does not require review by a research ethics board. An exemption letter was obtained by the Research Ethics Board at Women's College Hospital, Toronto, Ontario.

We identified a unique cohort of providers based on physicians' billings for in-person and virtual ambulatory visits. We excluded visits for non-Ontario residents and those with an invalid or missing health card number. We also excluded all physicians with clinical volumes that were inconsistent with an active practice during the pre-COVID-19 period ( $<10$ ambulatory visits during the period from January to June 2019).

We then calculated the ratio of total in-person and virtual ambulatory visits over the period from January to June 2020 (virtual predominating) relative to that over the period from January to June 2019 (in-person predominating) for each physician. We included first-quarter data in 2020 as they cover the beginning of the pandemic. Data extending past the second quarter of 2020 were unavailable. Based on these ratios, we then stratified physicians into four groups: (1) low-use physicians had ratios from 0 to 0.50 (ie, a $50 \%$ or greater reduction in visits in 2020 compared to 2019), (2) same-use physicians were those with ratios over 0.50 but less than 1.25 , (3) high-use physicians were those with ratios of at least 1.25 but less than 6.0, and (4) very high-use physicians were those with ratios equal to or greater than 6.0 (ie, an at-least 6-fold increase in visits in 2020 compared to 2019). To explore whether the proportions of physicians falling into each category differed much from previous years, we also calculated the number of physicians falling into each group — defined as the same ratio ranges - for the periods of January to June 2019 relative to January to June 2018.

For all physicians, we also obtained demographic and practice characteristics, including, age, sex, years since graduation, training location, practice type (ie, specialist, family practice, or focused family practice physicians focusing $50 \%$ or more of their practice in a specific type of care, such as psychotherapy [12]), and specialty. We also calculated the number of unique patients seen, number of total visits, number of virtual visits, and number of visits per day, virtual or any.

\section{Results}

Among 28,383 eligible physicians in 2020, the mean ratio of ambulatory visits in January to June 2020:2019 was 0.99 (SD 2.53; median 0.81, IQR 0.59-1.0). Only 291 physicians (1.0\%) were very high users, 2672 physicians $(9.4 \%)$ were high users, and $5422(19.1 \%)$ were low users (Figure 1). In comparison, the previous year (2019:2018 visit ratio), among 27,709 eligible physicians, $289(1.0 \%)$ were very high users, 3395 (12.3\%) were high users, and 2937 (10.6\%) were low users. 
Figure 1. Histogram showing the total number of physicians by ambulatory visit volume ratio (2020:2019). Proportions of $<1$ indicate fewer visits in the period of January to June 2020 when compared to January to June 2019, while a proportion of $>1$ suggested increased visits in the period of January to June 2020 . Note, the last bin in orange represents anybody with a ratio over 5.93, representing the top $1 \%$.

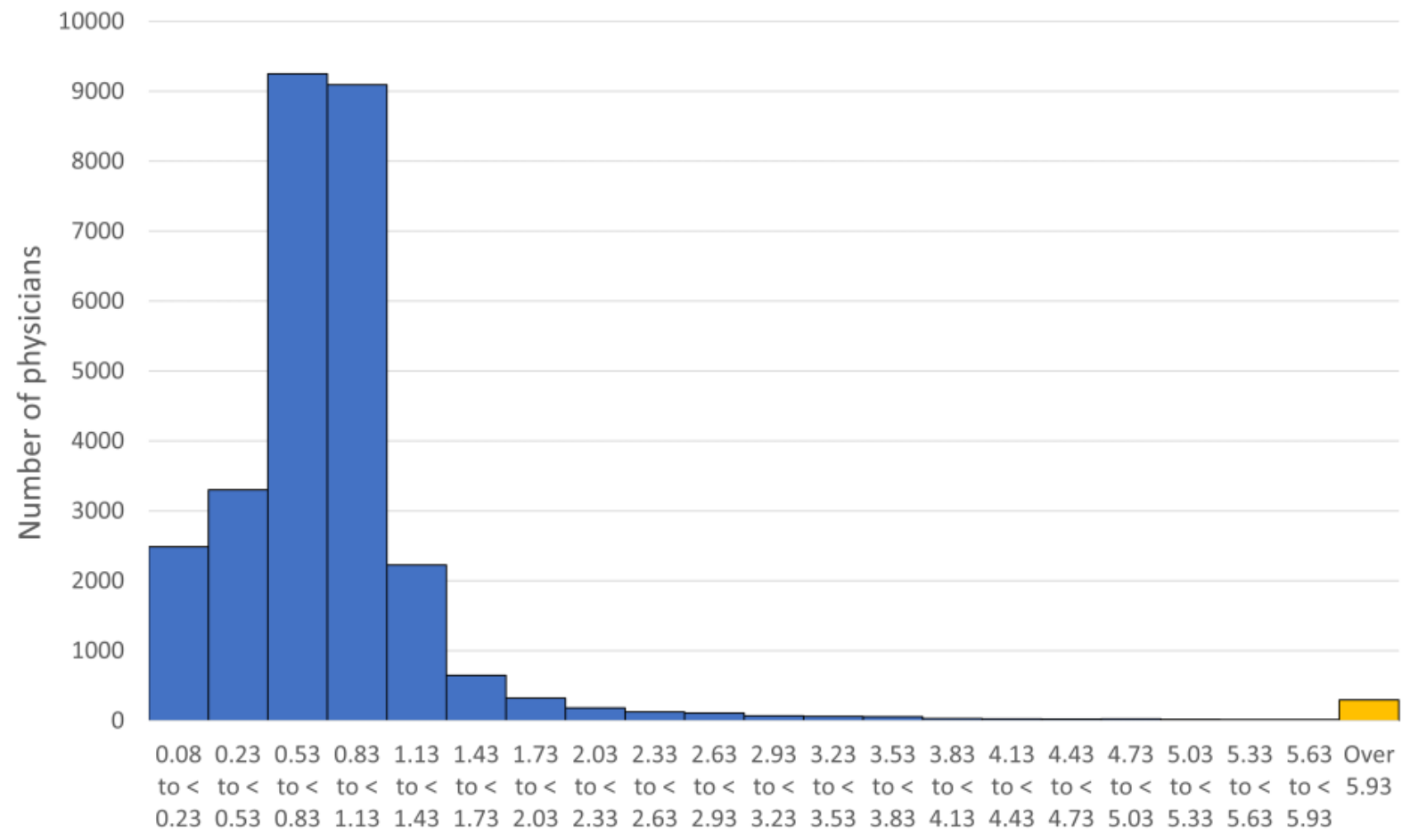

\section{Ratio of 2020 to 2019 ambulatory visits}

High-use physicians were younger, more recent graduates, more likely to be female, and less likely to be international graduates than those who maintained their volumes (ie, same-use group) $(P<.001)$ (Table 1). These effects were even more pronounced in the very high-use group. They were also more likely to be specialists than primary care providers $(P<.001)$, and physicians in focused primary care practices were more likely to be high or very high users relative to specialists $(P<.001)$.

Physicians in the two high-use groups had, on average, lower-volume practices in both 2020 and $2019(P<.001)$, and volumes were especially smaller in 2019 with fewer patients seen $(P<.001)$. The effect was larger for the very high users $(P<.001)$. Providers in the two high-use groups had fewer visits per billing day and fewer total patients seen in $2020(P<.001)$, but they had a higher percentage of virtual care visits $(P<.001)$ and a similar number of virtual care visits per day compared to the same-use group (Table 1).

Specialties with a large percentage of their total physician population being in the high-use group included emergency medicine $(41 / 230,17.8 \%)$, psychiatry $(378 / 2061,18.3 \%)$, and internal medicine $(147 / 999,14.7 \%)$. The same specialties were common among the very high-use group (Table 2).

Pearson correlations between the 2020:2019 visit ratio and percent of visits completed virtually showed a significant positive correlation only among physicians from the same-use group $(R=0.35, P<.001)$ (Figure 2$)$.

Finally, we also calculated the Pearson correlation coefficient between the average 2020:2019 ratio per specialty and the percent virtual care used per specialty. We excluded emergency medicine, diagnostic radiology, and nuclear medicine, as they were outliers and had both the highest 2020:2019 visit ratios $(1.6,1.3$, and 2.9 , respectively) and the lowest percentages of virtual care $(12.4 \%, 1.5 \%$, and $8.2 \%$, respectively). There was a significant positive correlation between the 2020:2019 ratio and the percent virtual care across specialties $(R=0.59, P<.01)$ (Figure 3). 
Table 1. Physician characteristics stratified by ratio of ambulatory visits in January to June 2020:2019.

\begin{tabular}{|c|c|c|c|c|c|c|}
\hline \multirow[t]{3}{*}{ Characteristic } & \multicolumn{5}{|l|}{ Physicians } & \multirow[t]{3}{*}{$P$ value } \\
\hline & All $(\mathrm{N}=28,383)$ & Low use: & Same use: & High use: & Very high use: & \\
\hline & & $\begin{array}{l}0 \text { to } 0.50 \text { visits }^{\mathrm{a}} \\
(\mathrm{n}=5422)\end{array}$ & $\begin{array}{l}>0.50 \text { to }<1.25 \text { visits } \\
(\mathrm{n}=19,998)\end{array}$ & $\begin{array}{l}1.25 \text { to }<6.0 \text { visits }^{\mathrm{b}} \\
(\mathrm{n}=2672)\end{array}$ & $\begin{array}{l}\geq 6.0 \text { visits } \\
(n=291)\end{array}$ & \\
\hline Age (years), mean (SD) & $53.9(11.2)$ & $56.1(12.6)$ & $53.7(10.8)$ & $51.9(11.24)$ & $49.2(11.5)$ & $<.001$ \\
\hline Years since graduation, mean (SD) & $25.1(13.3)$ & $26.7(15.5)$ & $25.4(12.5)$ & $20.5(12.60)$ & $15.8(11.7)$ & $<.001$ \\
\hline Sex (female), n (\%) & $11,864(41.8)$ & $2287(42.5)$ & $8116(40.6)$ & $1268(48.4)$ & $148(55.4)$ & $<.001$ \\
\hline $\begin{array}{l}\text { Canadian or internationally trained } \\
\text { (Canadian trained), } \mathrm{n}(\%)\end{array}$ & $16,218(76.4)$ & $2928(77.2)$ & $11,912(75.7)$ & $1282(81.6)$ & $96(83.5)$ & $<.001$ \\
\hline \multicolumn{7}{|c|}{ Number of unique patients seen in 2019 (January to June) } \\
\hline Mean (SD) & $729.2(795.0)$ & $496.53(675.0)$ & $858.28(828.8)$ & $308.81(433.4)$ & $55.46(60.5)$ & $<.001$ \\
\hline Median (IQR) & $539(163-999)$ & $257(75-689)$ & $691(295-1129)$ & $153(50-402)$ & $35(17-72)$ & $<.001$ \\
\hline \multicolumn{7}{|c|}{ Number of unique patients seen in 2020 (January to June) } \\
\hline Mean (SD) & $556.7(618.1)$ & $155.2(297.0)$ & $684.5(639.5)$ & $428.0(577.4)$ & $439.3(408.9)$ & $<.001$ \\
\hline Median (IQR) & $408(100-789)$ & $35(0-183)$ & $559(241-910)$ & $236(81-567)$ & $347(133-590)$ & $<.001$ \\
\hline \multicolumn{7}{|c|}{ Percent virtual care visits in 2020 (January to June) } \\
\hline Mean (SD) & $31.9(22.7)$ & $14.95(24.3)$ & $34.03(20.0)$ & $40.3(26.2)$ & $42.3(28.6)$ & $<.001$ \\
\hline Median (IQR) & $34(11-49)$ & $0(0-22)$ & $37(19-49)$ & $44(18-60)$ & $42(21-61)$ & $<.001$ \\
\hline \multicolumn{7}{|c|}{ Number of virtual care visits in 2020 (January to June) } \\
\hline Mean (SD) & $400.7(571.0)$ & $52.1(139.5)$ & $471.3(570.6)$ & $411.9(771.3)$ & $294.8(315.1)$ & $<.001$ \\
\hline Median (IQR) & $231(30-551)$ & $1(0-37)$ & $324(98-639)$ & $199(32-494)$ & $205(70-432)$ & $<.001$ \\
\hline \multicolumn{7}{|c|}{ Number of total visits in 2020 (January to June) } \\
\hline Mean (SD) & $1101.2(1228.9)$ & $292.2(484.9)$ & $1300.0(1257.7)$ & $877.9(1293.1)$ & $738.0(655.7)$ & $<.001$ \\
\hline Median (IQR) & $780(240-1503)$ & $108(23-370)$ & $1004(454-1715)$ & $495(151-1105)$ & $538(274-976)$ & $<.001$ \\
\hline \multicolumn{7}{|c|}{ Number of total visits in 2019 (January to June) } \\
\hline Mean (SD) & $1304.8(1420.4)$ & $800.5(1103.6)$ & $1561.5(1483.3)$ & $541.4(855.9)$ & $66.1(73.7)$ & $<.001$ \\
\hline Median (IQR) & $934(286-1799)$ & $392(101-1128)$ & $1212(539-2078)$ & $267(74-658)$ & $43(20-84)$ & $<.001$ \\
\hline \multicolumn{7}{|c|}{ Number of visits per billing day in 2020 (January to June) } \\
\hline Mean (SD) & $12.1(9.5)$ & $8.1(8.3)$ & $13.2(9.5)$ & $9.7(9.8)$ & $10.2(7.3)$ & $<.001$ \\
\hline Median (IQR) & $9(5-15)$ & $5(2-10)$ & $11(6-16)$ & $7(3-12)$ & $7(4-12)$ & $<.001$ \\
\hline \multicolumn{7}{|c|}{ Number of virtual visits per billing day in 2020 (January to June) } \\
\hline Mean (SD) & $8.6(6.7)$ & $5.0(5.2)$ & $9.1(6.5)$ & $8.1(7.6)$ & $7.4(5.4)$ & $<.001$ \\
\hline Median (IQR) & $7(4-11)$ & $3(2-6)$ & $7(4-11)$ & $6(3-10)$ & $6(3-9)$ & $<.001$ \\
\hline \multicolumn{7}{|l|}{ Practice type, n (\%) } \\
\hline Specialist & $15,201(53.6)$ & $3058(56.4)$ & $10,419(52.1)$ & $1590(59.5)$ & $134(46.0)$ & $<.001$ \\
\hline Primary care provider & $9393(33.1)$ & $1366(25.2)$ & $7560(37.8)$ & $436(16.3)$ & $31(10.7)$ & $\mathrm{N} / \mathrm{A}^{\mathrm{c}}$ \\
\hline Focused primary care provider ${ }^{\mathrm{d}}$ & $426(1.5)$ & $120(2.2)$ & $190(1.0)$ & $97(3.6)$ & $19(6.5)$ & N/A \\
\hline Miscellaneous & $3363(50.0)$ & $878(13.1)$ & $1829(27.2)$ & $549(8.2)$ & $107(1.6)$ & N/A \\
\hline
\end{tabular}

${ }^{\mathrm{a}}$ Visits of 0 to 0.50 correspond to physicians who had a $50 \%$ or greater reduction in ambulatory visits between 2019 and 2020.

${ }^{b}$ Visits of 1.25 to $<6$ correspond to physicians who had a 25\% 6-fold increase in visits between 2019 and 2020.

${ }^{\mathrm{c}}$ N/A: not applicable; a single test was conducted across all four groups in this section and the $P$ value is reported in the row for the first group.

${ }^{\mathrm{d}}$ Focused primary care providers are primary care providers who specialize in a specific care (eg, palliative care). 
Table 2. Physicians per specialty across each user group.

\begin{tabular}{|c|c|c|c|c|}
\hline Specialty & $\begin{array}{l}\text { Low use: } \\
0 \text { to } 0.5, \mathrm{n}(\%)\end{array}$ & $\begin{array}{l}\text { Same use: } \\
>0.5 \text { to }<1.25, \mathrm{n}(\%)\end{array}$ & $\begin{array}{l}\text { High use: } \\
1.25 \text { to }<6.0, \mathrm{n}(\%)\end{array}$ & $\begin{array}{l}\text { Very high use: } \\
\geq 6.0, \mathrm{n}(\%)\end{array}$ \\
\hline Family medicine $(n=13,244)$ & $2366(17.9)$ & $9715(73.4)$ & $1042(7.9)$ & $121(0.9)$ \\
\hline \multicolumn{5}{|l|}{ Medicine } \\
\hline Emergency medicine $(n=230)$ & $57(24.8)$ & $126(54.8)$ & $41(17.8)$ & $6(2.6)$ \\
\hline Internal medicine $(\mathrm{n}=999)$ & $233(23.3)$ & $604(60.5)$ & $147(14.7)$ & $15(1.5)$ \\
\hline Infectious diseases $(n=148)$ & $27(18.2)$ & $101(68.2)$ & $20(13.5)$ & $0(0)$ \\
\hline Critical care $(n=99)$ & $29(29.3)$ & $53(53.5)$ & $13(13.1)$ & $\leq 5(\leq 5.1)$ \\
\hline Endocrinology $(\mathrm{n}=269)$ & $18(6.7)$ & $215(79.9)$ & $34(12.6)$ & $\leq 5(\leq 1.9)$ \\
\hline Nuclear medicine $(n=48)$ & $15(31.3)$ & $24(50.0)$ & $6(12.5)$ & $\leq 5(\leq 10.4)$ \\
\hline Hematology $(n=217)$ & $23(10.6)$ & $164(75.6)$ & $27(12.4)$ & $\leq 5(\leq 2.3)$ \\
\hline Cardiology $(n=684)$ & $77(11.3)$ & $527(77.0)$ & $78(11.4)$ & $\leq 5(\leq 0.7)$ \\
\hline Respirology $(n=308)$ & $32(10.4)$ & $237(76.9)$ & $35(11.4)$ & $\leq 5(\leq 1.6)$ \\
\hline Geriatric medicine $(n=152)$ & $29(19.1)$ & $105(69.1)$ & $16(10.5)$ & $\leq 5(\leq 3.3)$ \\
\hline Rheumatology $(n=213)$ & $19(8.9)$ & $172(80.8)$ & $22(10.3)$ & $0(0)$ \\
\hline Anesthesiology $(\mathrm{n}=1179)$ & $480(40.7)$ & $597(50.6)$ & $101(8.6)$ & $\leq 5(\leq 0.4)$ \\
\hline Nephrology $(n=242)$ & $23(9.5)$ & $198(81.8)$ & $20(8.3)$ & $\leq 5(\leq 2.1)$ \\
\hline Clinical immunology $(n=84)$ & $22(26.2)$ & $56(66.7)$ & $6(7.1)$ & $0(0)$ \\
\hline Gastroenterology $(n=345)$ & $39(11.3)$ & $281(81.4)$ & $24(7.0)$ & $\leq 5(\leq 1.4)$ \\
\hline Obstetrics and gynecology $(\mathrm{n}=808)$ & $98(12.1)$ & $659(81.6)$ & $45(5.6)$ & $6(0.7)$ \\
\hline \multicolumn{5}{|l|}{ Other specialties } \\
\hline Psychiatry $(n=2061)$ & $328(15.9)$ & $1326(64.3)$ & $378(18.3)$ & $29(1.4)$ \\
\hline Diagnostic radiology $(n=624)$ & $179(28.7)$ & $355(56.9)$ & $84(13.5)$ & $6(1.0)$ \\
\hline Medical oncology $(n=269)$ & $34(12.6)$ & $200(74.3)$ & $35(13.0)$ & $0(0)$ \\
\hline Pediatrics $(n=1487)$ & $395(26.6)$ & $938(63.1)$ & $146(9.8)$ & $8(0.5)$ \\
\hline Radiation oncology $(n=211)$ & $14(6.6)$ & $178(84.4)$ & $19(9.0)$ & $0(0)$ \\
\hline Neurology $(n=410)$ & $53(12.9)$ & $321(78.3)$ & $33(8.0)$ & $\leq 5(\leq 1.2)$ \\
\hline $\begin{array}{l}\text { Physical medicine and rehabilitation } \\
(\mathrm{n}=211)\end{array}$ & $48(22.7)$ & $146(69.2)$ & $16(7.6)$ & $\leq 5(\leq 2.4)$ \\
\hline Dermatology $(n=236)$ & $52(22.0)$ & $173(73.3)$ & $11(4.7)$ & $0(0)$ \\
\hline Surgery $(n=2868)$ & $536(18.7)$ & $2212(77.1)$ & $104(3.6)$ & $16(0.6)$ \\
\hline Remaining smaller specialties $(n=384)$ & $91(23.7)$ & $246(64.1)$ & $43(11.2)$ & $4(1.0)$ \\
\hline Miscellaneous $(n=353)$ & $105(29.7)$ & $69(19.5)$ & $126(35.7)$ & $53(15.0)$ \\
\hline
\end{tabular}


Figure 2. Correlation between the 2020:2019 visit ratio and percent virtual care in the four groups of providers: those who reduced ( 0 to 0.50$)$, maintained $(>0.5$ to $<1.25)$, increased $(1.25$ to $<6)$, and significantly increased $(\geq 6)$ their practice in 2020 relative to 2019 .
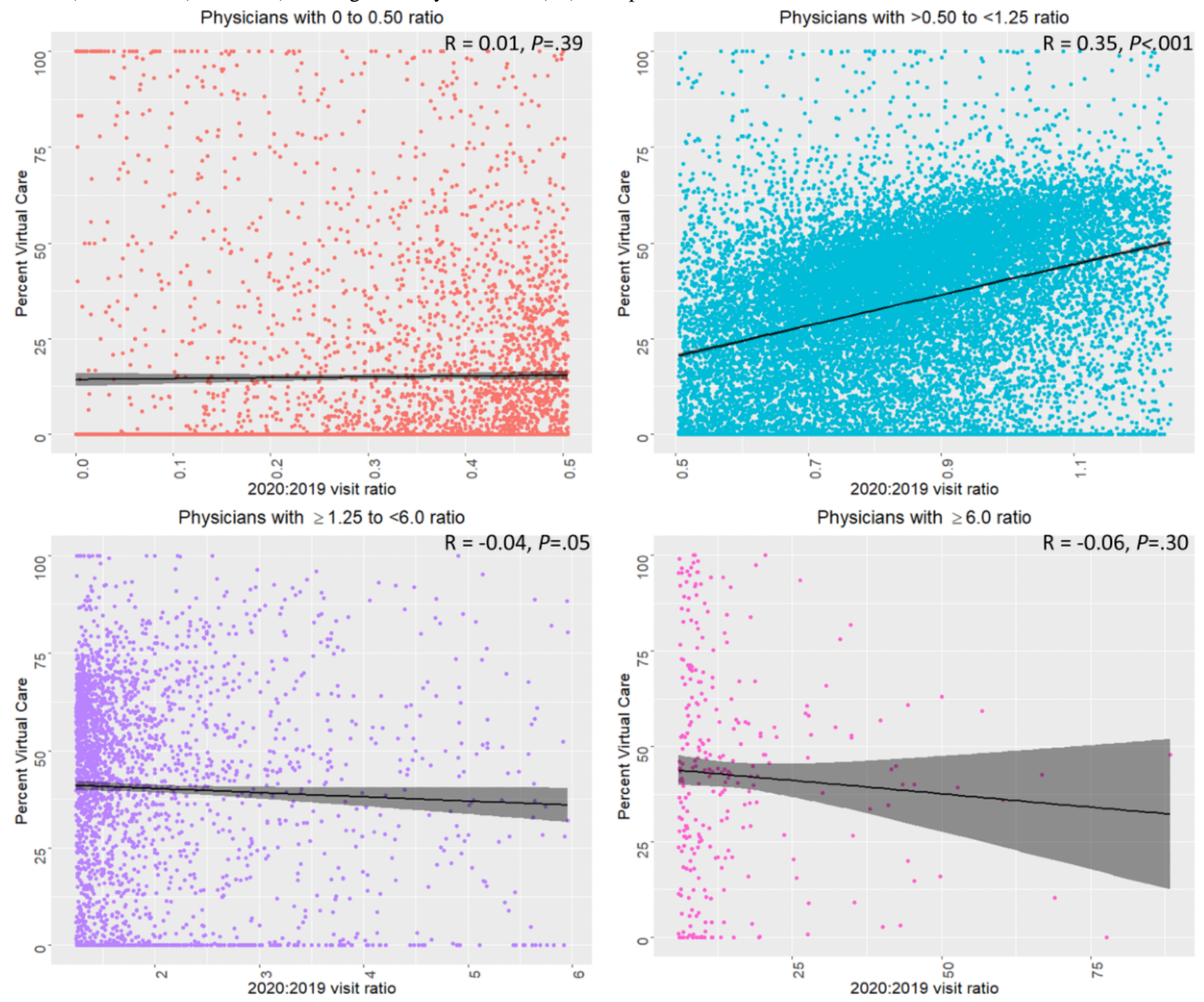

Figure 3. Correlation between the 2020:2019 visit ratio and virtual care adoption across specialties. The size of each sphere indicates the number of visits completed.

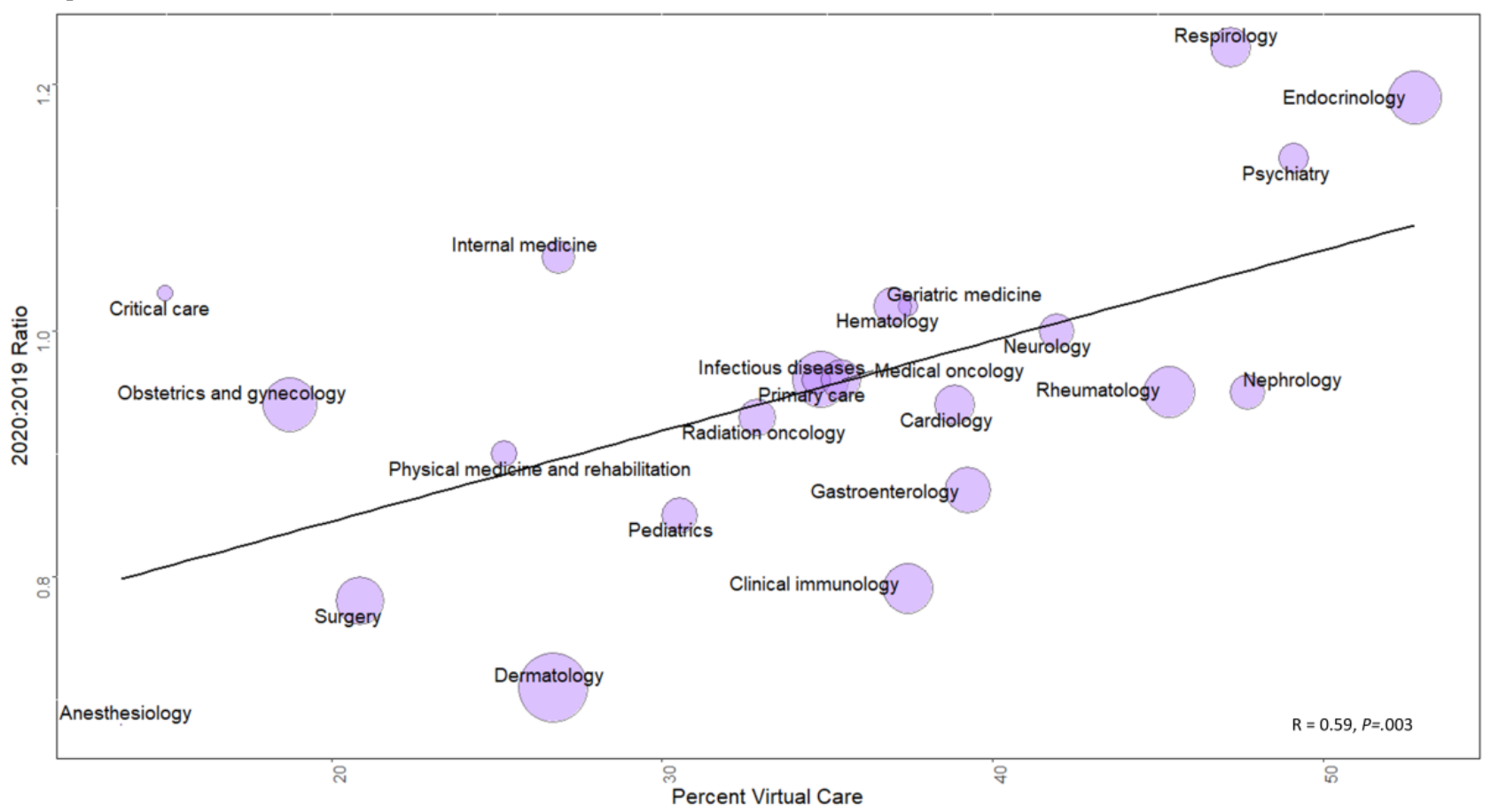




\section{Discussion}

During the early stages of the pandemic, the introduction of virtual care did not lead to significant increases in visit volume. Only about $10 \%$ of physicians increased their visit volumes by $25 \%$ or more in 2020 relative to 2019 . In total, our results provide reassuring evidence that relaxation of billing requirements early in the COVID-19 pandemic in Ontario were not associated with widespread and aberrant billing behaviors.

Providers who increased their visit volumes tended to be specialists, younger, more recent graduates, and more likely female. Among providers who increased their practice volumes, there was no relationship between the magnitude of increase and virtual care adoption. A significant relationship was observed, however, among providers who maintained their practice. This relationship was also maintained at the specialty level. Endocrinology, respirology, and psychiatry maintained their practices the best and had higher rates of virtual care adoption.

Our results are consistent with data from the United States that showed that despite the introduction of virtual care, overall visit volumes decreased in the early periods of the COVID-19 pandemic [6]. In fact, the introduction of virtual care during the pandemic allowed physicians to maintain their practices. Higher rates of virtual care use among providers who maintained their practice volumes were associated with better maintenance of visit volumes during the pandemic. This trend was also observed in the United States [6]. Here, we confirm these findings with an analysis of the entire physician and patient population in a health care system with a single insurance plan where the introduction of virtual care payment policies occurred at the same time for the entire population.

At least two specialties that showed high virtual care adoption rates and good maintenance of visit volumes during the pandemic were consistent in both Ontario and the United States [6]: psychiatry and endocrinology. Mental health care has the potential to be better suited for virtual care as it often does not require a physical exam and it has been successful in adopting virtual care services both before [13] and after the pandemic [14]. Successful adoption in endocrinology during the pandemic has also been reported [15].

Limitations to our study include a relatively brief time window for evaluating the impact of billing code liberalization, which makes it unclear whether the trends will be maintained in the long term. Our reliance on administrative data also precludes us from robustly evaluating appropriateness of individual visits.

In total, our study suggests that liberalization of virtual care billing requirements coinciding with the COVID-19 pandemic was not associated with an alarming increase in individual physician visit volumes and should serve to assuage concerns over widespread fraud. Furthermore, the strong relationship between the ability to maintain practice volumes and the use of virtual care suggest that the introduction of virtual care allowed continued access to care for patients.

\section{Conflicts of Interest}

None declared.

\section{References}

1. Baum A, Kaboli PJ, Schwartz MD. Reduced in-person and increased telehealth outpatient visits during the COVID-19 pandemic. Ann Intern Med 2021 Jan;174(1):129-131. [doi: 10.7326/m20-3026]

2. Patel SY, Mehrotra A, Huskamp HA, Uscher-Pines L, Ganguli I, Barnett ML. Trends in outpatient care delivery and telemedicine during the COVID-19 pandemic in the US. JAMA Intern Med 2021 Mar 01;181(3):388-391. [doi: 10.1001/jamainternmed.2020.5928] [Medline: 33196765]

3. Bhatia RS, Chu C, Pang A, Tadrous M, Stamenova V, Cram P. Virtual care use before and during the COVID-19 pandemic: A repeated cross-sectional study. CMAJ Open 2021;9(1):E107-E114 [FREE Full text] [doi: 10.9778/cmajo.20200311] [Medline: 33597307]

4. Mehrotra A, Bhatia RS, Snoswell CL. Paying for telemedicine after the pandemic. JAMA 2021 Feb 02;325(5):431-432. [doi: 10.1001/jama.2020.25706] [Medline: 33528545]

5. Digital transformation: Shaping the future of European healthcare. Deloitte United Kingdom.: Deloitte Centre for Health Solutions; 2020 Sep. URL: https://www2.deloitte.com/uk/en/pages/life-sciences-and-healthcare/articles/ european-digital-health.html [accessed 2021-03-01]

6. Patel SY, Mehrotra A, Huskamp HA, Uscher-Pines L, Ganguli I, Barnett ML. Variation in telemedicine use and outpatient care during the COVID-19 pandemic in the United States. Health Aff (Millwood) 2021 Feb;40(2):349-358. [doi:

10.1377/hlthaff.2020.01786] [Medline: 33523745]

7. Alexander GC, Tajanlangit M, Heyward J, Mansour O, Qato DM, Stafford RS. Use and content of primary care office-based vs telemedicine care visits during the COVID-19 pandemic in the US. JAMA Netw Open 2020 Oct 01;3(10):e2021476 [FREE Full text] [doi: 10.1001/jamanetworkopen.2020.21476] [Medline: 33006622]

8. OMA's Virtual Care FAQs. Toronto, ON: Ontario Medical Association; 2019 Nov 13. URL: https://ontariorheum.ca/ wp-content/uploads/Virtual-Care-OTN-FAQs-Nov-2019.pdf [accessed 2021-08-27]

9. Glauser W. Virtual care has potential to fragment primary care and disturb continuity of care, warn doctors. CMAJ News. 2019 Aug 29. URL: http://cmajnews.com/2019/08/29/ virtual-care-has-potential-to-fragment-primary-care-and-disturb-continuity-of-care-warn-doctors/ [accessed 2021-03-04] 
10. O'Dowd A. Doctors question Hancock's idea of GP video consultations for all. BMJ 2018 Sep 14;362:k3934. [doi: 10.1136/bmj.k3934] [Medline: 30217932]

11. Verma S. Early impact of CMS expansion of Medicare telehealth during COVID-19. Health Affairs Blog. 2020 Jul 15. URL: https://www.healthaffairs.org/do/10.1377/hblog20200715.454789/full/ [accessed 2021-04-01]

12. Schultz SE, Glazier RH. Identification of physicians providing comprehensive primary care in Ontario: A retrospective analysis using linked administrative data. CMAJ Open 2017 Dec 19;5(4):E856-E863 [FREE Full text] [doi: 10.9778/cmajo.20170083] [Medline: 29259018]

13. Mehrotra A, Huskamp HA, Souza J, Uscher-Pines L, Rose S, Landon BE, et al. Rapid growth in mental health telemedicine use among rural Medicare beneficiaries, wide variation across states. Health Aff (Millwood) 2017 May 01;36(5):909-917. [doi: 10.1377/hlthaff.2016.1461] [Medline: 28461359]

14. Connolly SL, Stolzmann KL, Heyworth L, Weaver KR, Bauer MS, Miller CJ. Rapid increase in telemental health within the Department of Veterans Affairs during the COVID-19 pandemic. Telemed J E Health 2021 Apr;27(4):454-458. [doi: 10.1089/tmj.2020.0233] [Medline: 32926664]

15. Madduri S, Chowdhary R, Sethu Reddy S. Telehealth adoption among endocrinologists during the COVID-19 pandemic. Endocr Pract 2020 Aug;26(8):846-856. [doi: 10.4158/ep-2020-0237]

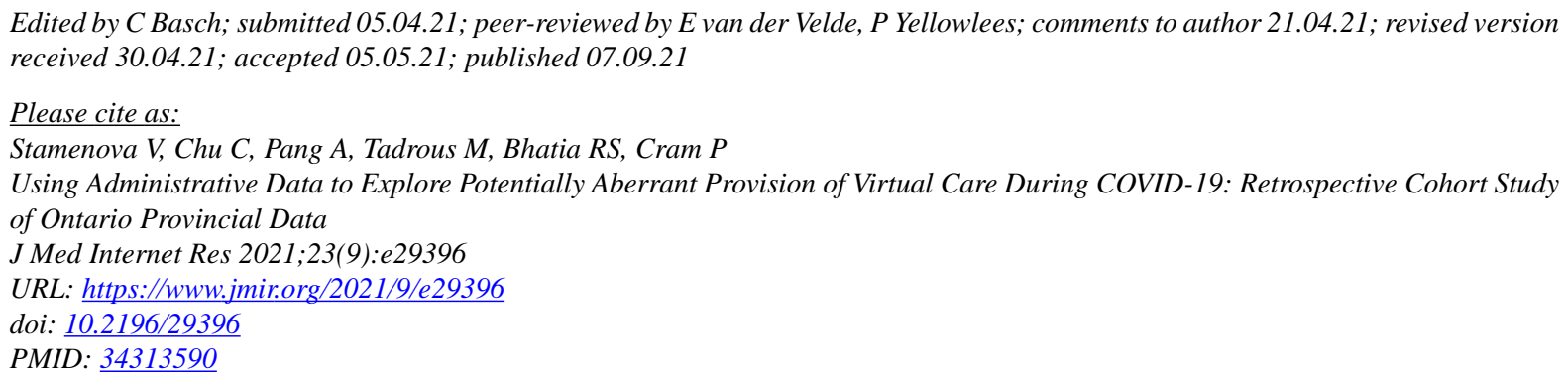

(C) Vess Stamenova, Cherry Chu, Andrea Pang, Mina Tadrous, R Sacha Bhatia, Peter Cram. Originally published in the Journal of Medical Internet Research (https://www.jmir.org), 07.09.2021. This is an open-access article distributed under the terms of the Creative Commons Attribution License (https://creativecommons.org/licenses/by/4.0/), which permits unrestricted use, distribution, and reproduction in any medium, provided the original work, first published in the Journal of Medical Internet Research, is properly cited. The complete bibliographic information, a link to the original publication on https://www.jmir.org/, as well as this copyright and license information must be included. 